\title{
Prevalence of Latent Tuberculosis Infection among Paramedical Students in Two Hospitals in Uganda
}

\author{
Dr. Isaac Okullo ${ }^{1}$, Dr. Felix Kaducu ${ }^{2}$, Dr. Achilles Katamba ${ }^{3}$, Louis Muwazi ${ }^{*}$, Dr. Moses \\ Nkamba $^{1}$, Dr. Annet Kutesa ${ }^{1}$, Charles Mugisha Rwenyonyi ${ }^{1}$ \\ ${ }^{1}$ Department of Dentistry, School of Health Sciences, College of Health Sciences, Makerere \\ University, Kampala, Uganda \\ ${ }^{2}$ Department of Public Health, Faculty of Medicine, Gulu University, Gulu, Uganda \\ ${ }^{3}$ Department of Internal Medicine, School of Medicine, College of Health Sciences, Makerere \\ University, Kampala, Uganda
}

*Corresponding Author: Louis Muwazi, Department of Dentistry, School of Health Sciences, College of Health Sciences, Makerere University, Kampala, Uganda

\begin{abstract}
The risk of transmission of Mycobacterium tuberculosis to health-care workers in many low and middleincome countries is greater when large numbers of infectious (smear positive) tuberculosis (TB) patients are managed at health facilities. The present study was carried out in Mulago and Gulu teaching hospitals in Uganda among 291 students on the Public Health Dentistry $(n=73)$, Clinical Officers $(n=92)$ and Nursing $(n=126)$ programmes to determine their latent TB infection status. Socio-demographic factors of the participants were recorded and TST induration was read after 48 to 72 hours. Chi-square statistics were used to compare latent $T B$ infection among pre-clinic and clinical year students in different study programmes. About $87 \%(n=254)$ of the respondents had Bacillus Calmette-Guérin vaccination skin scar. Of the 291 respondents (response rate, 89.5\%), 92.4\% developed an induration after TST. The mean diameter of the induration was $12.61 \mathrm{~mm}$ (95\% CI: 11.95-13.26). A prevalence of latent TB infection (80.4\%) with TST induration reading of $\geq 10 \mathrm{~mm}$ was found among the respondents. Significantly more Nursing had an induration $\geq 10 \mathrm{~mm}$ than the Dental $(p=0.046)$ and the Clinical Officer students $(p=0.047)$. The observed prevalence of latent TB infection was high, indicating a high level of transmission of Mycobacteria tuberculosis among the young health worker students, which is a risk to patients under their care. It is important to screen trainees upon entering into the study programmes in order to determine the magnitude of latent TB infection for better policy guidance.
\end{abstract}

Keywords: clinical officer; dentistry; latent TB; nursing students; prevalence; tuberculin skin test

\section{INTRODUCTION}

The risk of transmission of Mycobacterium tuberculosis from patients to health-care workers (HCWs) is a neglected problem in many low and middle-income countries (LMICs) although it has been well recognized over the years ${ }^{1-3}$. Most healthcare facilities in LMICs lack resources to prevent hospital transmission of tuberculosis (TB), yet as pointed out in the World Health Organisation (WHO) guidelines ${ }^{4}$, it affects the personal health of health care workers (HCWs) and may result in either temporary or permanent loss of HCWs from the workforce. The risk of such transmission is even greater when larger numbers of infectious (smear positive) TB patients are managed at health facilities, and this could be reduced with implementation of effective infection control measures ${ }^{5,6}$.
In a Turkish study, Hosoglu et al. ${ }^{7}$ showed that HCWs and medical, and nursing students with patient contact are at increased risk for acquisition of TB infection and development of the disease.

In the case of latent $\mathrm{TB}$ infection (i.e. persons infected with TB, but without symptoms), HCWs are particularly at higher risk of acquiring the infection than the general population as a result of their possible contact to patients with TB infection. In addition, should HCWs develop active TB infection, they are more likely to transmit the infection to their patients, especially those patients who are immuno-suppressed ${ }^{8}$.

In a systematic review, Baussano et al. $^{9}$ concluded that HCWs are at higher risk for infection with Mycobacterium tuberculosis and 
of developing TB disease than the general population. They recommended that sound TB infection control measures, including early diagnosis and prompt treatment of infectious cases, should be prioritized. Though a number of tests for TB diagnosis exists, tuberculin skin test (TST) being relatively nonspecific with both modest false positive and false negative results, remains a very useful and indeed a critical tool both for epidemiologic research, the control and prevention of clinical tuberculosis ${ }^{10,11}$, especially in resource poor settings like Uganda. Furthermore, Nelson ${ }^{11}$ revealed that although the practice, timing and frequency of Bacillus Calmette-Guérin (BCG) vaccination, the type of test material i.e. tuberculin purified protein derivative (TPPD), technique of TST reading, and definition of a positive test can be an important cause of false-positive TST, they do not affect the analysis of the risk factors associated with latent TB infection.

In Uganda, the prevalence of TB infection in the household contacts surveyed between 1995 and 1999 in Kampala was found to be $66 \%{ }^{12}$. In another study among HCWs in Kampala carried out in 2001, the prevalence of latent TB infection was found to be $57 \%{ }^{13}$. Given the relatively high prevalence of TB infection among the general population in Uganda, it is appropriate to establish the burden of the disease among students in health training institutions and to our knowledge no such study has been published. The aim of the present study was to determine the prevalence of latent TB infection among paramedical students in Mulago and Gulu hospitals, Uganda.

\section{METHODS}

\section{Study Setting and Population}

The study was carried out in Mulago and Gulu hospitals in February 2015. Mulago Hospital is the biggest health facility that trains health workers in Uganda located in the capital city, Kampala. It has a number of different health specialties making it appropriate for training of different categories of paramedical professionals such as Public Health Dental officers (Dental), Nurses, Radiographers, Orthopeadic officers, Laboratory technicians and Physiotherapists. On the other hand, Gulu Hospital, located $330 \mathrm{~km}$ north of Kampala, is a regional referral facility. It is a training center for Clinical Officers (COs), one of the vital categories of health professionals that is not trained at Mulago Hospital. The study included students on Dental, Nursing and COs diploma programmes who were purposively selected because their training environment brings them into close contact with patients, thus promoting cross transmission of pathogenic micro-organisms. Furthermore, these are programmes where students stay for three years in training and are assumed to have prolonged contact with patients.

\section{Study Design}

This was a descriptive cross sectional study. For purposes of representative sampling, the study participants were stratified according to the 3 study programmes from which all first year, i.e. preclinical students (with minimal clinical exposure) and all third year, i.e. clinical students (with a longer clinical exposure) were selected.

\section{Sampling Procedure}

All the three institutions had a total of 581 students enrollment in year one and year three in the three programmes. Using Epi info 7 Statcalc, the sample size for this population of students using 95\% Confidence Level, 50\% Expected Frequency and 5\% Confidence Limit, was found to be 231. However, a total of 331 students, age range, 19 to 30 years consented and were all recruited in order to increase statistical power and cater for loss to follow up. Six of the participants who had either history of chronic medical conditions or past history of active TB were excluded leaving a total of 325 .

\section{Protocol for Administration and Reading of TST}

Quantitative data were collected following the TST as previously described ${ }^{14,15}$. Visual inspection was done to check for the BCG vaccination skin scar. On account of the anticipated low prevalence of human immunodeficiency virus (HIV) in this generally young healthy looking cohort $^{16}$, we did not perform HIV testing and we restricted the invasive procedure to TST.

Under aseptic conditions, $0.1 \mathrm{ml}$ equivalent to 5 units of TPPD (Tubersol, Connaught Laboratories, Toronto, Canada) were injected intra-dermally into the volar aspect of the left forearm of 325 participants using a $0.5 \mathrm{ml}$ syringe and a 27 gauge needle (Sherwood Medical Company, St. Louis, MO, USA) by a trained nurse. The date and time of injection of the tuberculin purified protein derivative were recorded on the participant's record form. The participants were advised not to scratch the injection site in the event of itching and to return 48 to 72 hours after injection for the reading. 
The socio-demographic and TST data were recorded on a form designed for the purpose. Thirty four participants did not return for TST reading leaving 291: Dental $(n=73)$, Nursing $(\mathrm{n}=126)$ and COs $(\mathrm{n}=92)$ (Table 1).

Table1. The frequency distribution of participants according to socio-demographic and immunologic factors of associated with tuberculosis $(n=291)$

\begin{tabular}{|c|c|c|c|}
\hline Variable & Category & Number & Percent \\
\hline \multirow[t]{2}{*}{ Sex } & Male & 132 & 45.4 \\
\hline & Female & 159 & 54.6 \\
\hline \multirow[t]{2}{*}{ Age } & $19-24$ & 170 & 58.6 \\
\hline & $25-30$ & 121 & 41.4 \\
\hline \multirow{3}{*}{$\begin{array}{l}\text { Study } \\
\text { programme }\end{array}$} & Dental & 74 & 25.4 \\
\hline & Nursing & 126 & 43.3 \\
\hline & \begin{tabular}{|l|}
$\begin{array}{l}\text { Clinical } \\
\text { officer }\end{array}$ \\
\end{tabular} & 91 & 31.3 \\
\hline \multirow{2}{*}{$\begin{array}{l}\text { Year of } \\
\text { study }\end{array}$} & 1 (preclinical) & 162 & 56.7 \\
\hline & 3 (clinical) & 129 & 44.3 \\
\hline \multirow{2}{*}{$\begin{array}{l}\text { Are you on } \\
\text { medication? }\end{array}$} & Yes & 24 & 8.2 \\
\hline & No & 267 & 91.8 \\
\hline \multirow{4}{*}{$\begin{array}{l}\text { If yes, list } \\
\text { the } \\
\text { medicines } \\
(n=24)\end{array}$} & Antibiotics & 19 & 79.2 \\
\hline & Pain killers & 3 & 12.5 \\
\hline & Cough linctus & 1 & 4.2 \\
\hline & Herbs & 1 & 4.2 \\
\hline \multirow{2}{*}{$\begin{array}{l}\text { BCG skin } \\
\text { scar present }\end{array}$} & Yes & 254 & 87.3 \\
\hline & No & 37 & 12.7 \\
\hline \multirow{2}{*}{$\begin{array}{l}\text { Induration } \\
\text { present }\end{array}$} & Yes & 269 & 92.4 \\
\hline & No & 22 & 7.6 \\
\hline
\end{tabular}

BCG - Bacillus Calmette-Guérin

All TST readings were carried out by the Principal Investigator (IO) 48 to 72 hours following intra-dermal administration of the antigen. An induration was considered present if it was hard, dense and raised. A light, gentle motion of the first and middle fingertips was run over the surface of the volar aspect of the left arm to locate the margins or edges of the induration. In case of difficulty in identifying the edges of the induration, the elbow was flexed up to 45 degrees to enhance visibility of the induration. The longest diameter of the induration (transverse to the long axis of the forearm) was measured in millimetres using a plastic flexible ruler (Avery, United Kingdom). The area of erythema was not included in the measurement. In order to reduce measurement errors, duplicate readings were taken and the average was recorded. Interpretation of the TST was based on specific guidelines (Table 2).

Furthermore, blind duplicate reading for TST of 30 participants was done a day after the main examination for reliability test. The Cohen's kappa value was 0.84 , with no evidence of systematic errors ( $\mathrm{p}>0.05$, paired $\mathrm{t}$ test).

Table2. The criteria $^{17,18}$ for interpretation of the tuberculin skin test results

\begin{tabular}{|l|l|l|}
\hline $\begin{array}{l}\text { Diameter of } \\
\text { Induration }\end{array}$ & \multicolumn{1}{|c|}{ Interpretation } & \multicolumn{1}{|c|}{ Action } \\
\hline$\leq 5 \mathrm{~mm}$ & Negative & $\begin{array}{l}\text { If previously } \\
\text { unvaccinated, } \\
\text { students will be } \\
\text { advised to get } \\
\text { BCG provided } \\
\text { there are no } \\
\text { contraindications }\end{array}$ \\
\hline$>5 \mathrm{~mm}$ or & $\begin{array}{l}\text { Hypersensitive to } \\
\text { tuberculin protein. } \\
\text { This may be due to } \\
\text { previous TB } \\
\text { infection, BCG or } \\
\text { exposure to atypical } \\
\text { mycobacteria }\end{array}$ & $\begin{array}{l}\text { No action will be } \\
\text { taken }\end{array}$ \\
\hline$\geq 10 \mathrm{~mm}$ & $\begin{array}{l}\text { Strongly } \\
\text { hypersensitive to } \\
\text { tuberculin protein, } \\
\text { This is suggestive } \\
\text { of TB infection or } \\
\text { disease }\end{array}$ & $\begin{array}{l}\text { The student will } \\
\text { be referred for } \\
\text { further } \\
\text { investigations } \\
\text { and } \\
\text { management. }\end{array}$ \\
\hline
\end{tabular}

BCG - Bacillus Calmette-Guérin; TB - Tuberculosis

The primary outcome for this study was latent TB infection defined as TST with an induration of $\geq 10 \mathrm{~mm}$ in diameter ${ }^{17,18}$.

Due to limited funding, we could not carry out radiological or microbiological investigations on participants who tested positive for TST. However, they were advised to seek further evaluation in the specialised units of the respective hospitals.

\section{Data Analyses}

The data was cleaned and checked for errors, and completeness by a statistician before analysis using Statistical Package for Social Sciences Inc. (SPSS, version 17 for windows, Chicago, Illinois, USA). The frequency distribution was used to describe the material. One sample t test was used to assess whether the diameter of the induration was significantly different from zero and $95 \%$ confidence interval was generated around the mean of diameter of induration. Chi-square $\left(\chi^{2}\right)$ tests were used to compare frequency distributions of the respondents on the basis of the prevalence of latent $\mathrm{TB}$ infection and duration of clinical exposure in different programmes of study. Paired $t$ test was used to assess intra-examiner 
reliability in recording TST induration. A pvalue of $\leq 0.05$ was considered significant.

\section{Ethical Considerations}

All procedures conformed to protocol approved by Makerere University, School of Health Sciences Institutional Review Board, Uganda National Council for Science and Technology, and the respective hospital research and ethics committees. The selected study participants were approached for consent to participate in the study, first by notification through a large meeting, then individually in confidence. Consenting participants signed a written consent form in accordance with Helsinki Declaration ${ }^{19}$.

\section{RESULTS}

In Gulu Hospital, there were no dental and nursing students while in Mulago there were no clinical officer students (Table 1), hence the data were pooled. The age of the respondents ranged from 19 to 30 (mean, $23.4 \pm 5.6$ ) years. More than half of the respondents (56.7\%) were in their first year of study. The majority of the respondents $(91.7 \%)$ were not taking any medication. About $87 \%$ had BCG vaccination skin scar (Table 1). Of the 291 respondents who returned for the reading after tuberculin skin test (response rate $89.5 \%$ ), 92.4\% developed an induration (Table 1). The mean diameter of the induration was $12.61 \mathrm{~mm}(95 \% \mathrm{CI}$ : $11.95-$ 13.26). The majority of the respondents $(80.4 \%)$ had an induration of at least $10 \mathrm{~mm}$ in diameter.

There was no significant difference in the diameter of indurations between the pre-clinical and clinical students in different programmes of study ( $\mathrm{p}>0.05, \chi^{2}$ test, Table 3 ).

Table3. The frequency distribution of participants based on the diameter of induration after tuberculin skin test and year of study according to study programme $(n=291)$

\begin{tabular}{|c|c|c|c|c|}
\hline \multirow{2}{*}{$\begin{array}{c}\text { Study } \\
\text { Programme }\end{array}$} & \multirow[t]{2}{*}{ Diameter } & \multicolumn{2}{|c|}{ Year of study } & \multirow{2}{*}{$\begin{array}{c}P \text { P- } \\
\text { value }\end{array}$} \\
\hline & & $\begin{array}{c}1 \\
\text { (preclinical) }\end{array}$ & $\begin{array}{c}\mathbf{3} \\
\text { (clinical) }\end{array}$ & \\
\hline \multirow{2}{*}{$\begin{array}{c}\text { All } \\
\text { participants }\end{array}$} & $<10 \mathrm{~mm}$ & $37(22.8)$ & $20(15.5)$ & \multirow[t]{2}{*}{0.077} \\
\hline & $\geq 10 \mathrm{~mm}$ & $125(77.2)$ & $109(84.5)$ & \\
\hline \multirow{2}{*}{$\begin{array}{l}\text { Dental } \\
(\mathrm{n}=73)\end{array}$} & $<10 \mathrm{~mm}$ & $11(35.5)$ & $7(16.7)$ & \multirow[t]{2}{*}{0.059} \\
\hline & $\geq 10 \mathrm{~mm}$ & $20(64.5)$ & $35(83.3)$ & \\
\hline \multirow{2}{*}{$\begin{array}{l}\text { Nurses } \\
(\mathrm{n}=126)\end{array}$} & $<10 \mathrm{~mm}$ & $14(17.7)$ & $3(6.4)$ & \multirow[t]{2}{*}{0.059} \\
\hline & $\geq 10 \mathrm{~mm}$ & $65(82.3)$ & 44 (93.6) & \\
\hline \multirow{2}{*}{$\begin{array}{c}\text { Clinical } \\
\text { officers } \\
(n=92)\end{array}$} & $<10 \mathrm{~mm}$ & $12(23.1)$ & $10(25.0)$ & \multirow[t]{2}{*}{0.511} \\
\hline & $\geq 10 \mathrm{~mm}$ & $40(76.9)$ & $30(75.0)$ & \\
\hline
\end{tabular}

However comparison between programmes showed that significantly more Nursing had an induration $\geq 10 \mathrm{~mm}$ than the Dental $(\mathrm{p}=0.046)$ and the $\mathrm{CO}$ students $(\mathrm{p}=0.047)$. On the other hand, there was no statistically significant difference in the diameter of the induration between the Dental and CO students (Table 4).

Table4. The relationship between the participants according to diameter of the induration and study programme $(n=291)$

\begin{tabular}{|l|l|l|l|}
\hline \multirow{2}{*}{$\begin{array}{c}\text { Study } \\
\text { Programme }\end{array}$} & \multicolumn{2}{|c|}{$\begin{array}{c}\text { Diameter of } \\
\text { Induration }\end{array}$} & \multirow{2}{*}{ P-value } \\
\cline { 2 - 3 } & $\begin{array}{c}\mathbf{1 0} \mathbf{~ m m , ~ n} \geq \mathbf{1 0 ~ m m , ~ n} \\
(\mathbf{\%})\end{array}$ & \\
\hline Dental & $17(23.3)$ & $55(75.3)$ & \multirow{2}{*}{0.046} \\
\hline Nursing & $17(13.4)$ & $109(86.5)$ & \\
\hline Dental & $17(23.3)$ & $5575.3)$ & 0.912 \\
\hline Clinical officer & $22(23.9)$ & $70(76.1)$ & \\
\hline Nursing & $17(13.4)$ & $109(86.5)$ & 0.047 \\
\hline Clinical officer & $22(23.9)$ & $70(76.1)$ & \\
\hline
\end{tabular}

\section{DISCUSSION}

In the present study, the prevalence of latent TB infection was $80.4 \%$, which is quite high and this may contribute to loss of these skilled workers with adverse impact on health care services in the long run. This is in support of the evidence that hospital acquired TB infection is an important occupational problem among $\mathrm{HCW}$ in LMICs and reduction of that risk should be a priority ${ }^{2}$. In Uganda, Clinical Officers, Public Health Dental Officers and Nurses form the backbone of clinical care in the majority of health facilities, thus the reason trainees in these health fields were targeted in this study.

In the present study, an induration of $<10 \mathrm{~mm}$ was considered negative for latent TB infection (Table 2) because TB infection is endemic in Uganda $^{12}$. Since there is strong evidence that hospital acquired TB infection is an important occupational problem among HCWs in LMICs (2) and the present respondents are expected to join the workforce shortly after graduating, their health is a matter of concern for continued health care delivery to the majority of Ugandans. In addition, transmission of TB infection can have serious and even fatal consequences for patients at risk. This is particularly true with multidrug resistant (MDR)-TB strains ${ }^{2}$.

The prevalence of latent TB infection in the present study is higher than in previous surveys $^{12,13}$ in Kampala, Uganda where values of $57 \%$ and $66 \%$ of TST induration $\geq 10 \mathrm{~mm}$ were reported. Kayanja et al. ${ }^{13}$ postulated that health workers from clinical departments are at greater risk for latent $\mathrm{TB}$ infection due to regular contact with infectious cases in the clinics and wards. 
In the present study, there was a significantly higher proportion of students with latent TB infection on Nursing compared to the Dental and $\mathrm{CO}$ programmes (Table 4). This may be explained by the longer time Nursing students spend in close proximity with the patients and most times without protective face masks. Generally, there is a significantly higher rate of latent TB infection among the clinical compared to preclinical health workers ${ }^{13}$, however, this was not reflected in the present study which may be explained by the fact that the preclinical students are never exclusively banned from clinical session. Additionally, the measurement of latent TB in the present study was done when the students had been in the institution for quite some time and it was not possible to assess whether the participants acquired the TB infection from the patients they were in contact with or were already infected before they enrolled onto the study programmes. Different results could probably have been obtained with students tested on immediately joining the institution, suggestive of further studies.

We found the majority (87.3\%) of the participants had BCG vaccination skin scar in line with Uganda Ministry of Health policy of early vaccination against TB infection. The fact that we could not observe the scars in about $13 \%$ of the participants does not mean that they were not vaccinated since not all BCG vaccinations lead to skin scar formation. We relied on the presence of a skin scar because BCG vaccination is routinely done at day one of birth. However, not everyone vaccinated gets a scar and because of lack of knowledge of the respondents of what took place at that early age, underreporting may not be ruled out. It may be postulated that the high prevalence of latent TB infection in this study could have been contributed to by BCG vaccination. Although sensitivity to tuberculin purified protein derivative can also be induced by BCG vaccination, history of $B C G$ vaccination should be ignored when interpreting TST values in countries with high incidence of tuberculosis ${ }^{20}$, including Uganda.

\section{CONCLUSION/RECOMMENDATION}

This group of young paramedical students had a high prevalence of latent TB infection, which suggests a high level of transmission of Mycobacteria tuberculosis among students in health training institutions and a risk to patients under their care. This risk is significantly more prominent among nursing compared to the other paramedical students. Within the limitation of this cross-sectional study, it was not possible to determine whether the students acquired TB infection before or after enrolling into the different study programmes. It is important to screen trainees upon entering into the study programmes in order to determine the magnitude of latent $\mathrm{TB}$ infection for better policy guidance.

\section{COMPETING INTERESTS}

The authors declare that there are no competing interests.

\section{Authors CONTRIbutions}

IO, LM, CMR contributed to the design of the study. $\mathrm{MN}, \mathrm{AK}^{1}, \mathrm{AK}^{3}, \mathrm{FK}$ collected and evaluated the data. CMR and IO did the analysis of the data. All authors contributed to the preparation of the manuscript and approval of the final version.

\section{ACKNOWLEDGEMENTS}

The authors are grateful to the study participants for their cooperation. The Directors of the training institutions and ward managers were instrumental in mobilizing the participants. The THRiVE grant through Makerere University College of Health Sciences funded the study.

\section{REFERENCES}

[1]. Fennelly KP, Iseman MD. Health care workers and tuberculosis: the battle of a century [Editorial]. International Journal of Tuberculosis and Lung Disease. 1999 May 1;3(5):363-364.

[2]. Joshi R, Reingold AL, Menzies D, Pai M. Tuberculosis among health-care workers in low-and middle-income countries: a systematic review. PLoS Medicine. 2006 Dec 26;3(12):e494.

[3]. Sepkowitz KA. Tuberculin skin testing and the health care worker: lessons of the Prophit Survey. Tubercle and Lung Disease. 1996 Feb 29;77(1):81-85.

[4]. Jarvis WR, Espinal MA, Rieder HL, Granich R, Kumaresan JA, Simone PM, Binkin NJ, World Health Organization. Guidelines for the prevention of tuberculosis in health care facilities in resource-limited settings.

[5]. Harries AD, Maher D, Nunn P. Practical and affordable measures for the protection of health care workers from tuberculosis in low-income countries. Bulletin of the World Health Organization. 1997;75(5):477-489.

[6]. Jensen PA, Lambert LA, Iademarco MF, Ridzon R, Centers for Disease Control and Prevention. Guidelines for preventing the 
transmission of Mycobacterium tuberculosis in health-care settings, 2005. US Department of Health and Human Services, Public Health Service, Centers for Disease Control and Prevention; 2005 Dec 30.

[7]. Hosoglu S, Tanrikulu AC, Dagli C, Akalin S. Tuberculosis among health care workers in a short working period. American Journal of Infection Control. 2005 Feb 28;33(1):23-26.

[8]. Gershon AS, McGeer A, Bayoumi AM, Raboud J, Yang J. Health care workers and the initiation of treatment for latent tuberculosis infection. Clinical Infectious Diseases. 2004 Sep 1;39(5):667-672.

[9]. Baussano I, Nunn P, Williams B, Pivetta E, Bugiani M, Scano F. Tuberculosis among health care workers. Emerging Infectious Diseases. 2011 Mar 1;17(3):488-495.

[10]. Gustafson P, Lisse I, Gomes V, Vieira CS, Lienhardt C, Nauclér A, Jensen H, Aaby P. Risk factors for positive tuberculin skin test in Guinea-Bissau. Epidemiology. 2007 May 1;18(3):340-347.

[11]. Nelson K. Tuberculin testing to detect latent tuberculosis in developing countries. Epidemiology. 2007 May 1;18(3):348-349.

[12]. Guwatudde D, Nakakeeto M, Jones-Lopez EC, Maganda A, Chiunda A, Mugerwa RD, Ellner JJ, Bukenya G, Whalen CC. Tuberculosis in household contacts of infectious cases in Kampala, Uganda. American Journal of Epidemiology. 2003 Nov 1;158(9):887-898.

[13]. Kayanja HK, Debanne S, King C, Whalen CC. Tuberculosis infection among health care workers in Kampala, Uganda. International Journal of Tuberculosis and Lung Disease. 2005 Jun 1;9(6):686-688.

[14]. American Thoracic Society, Centers for Disease Control and Prevention. Targeted tuberculin testing and treatment of latent tuberculosis infection. American Journal of Respiratory Critical Care Medicine. 2000;161:S221-47.

[15]. Lordi GM, Reichman LB. Tuberculin skin testing. InTuberculosis 1994 (pp. 63-68). Springer New York.

[16]. Ministry of Health. Uganda AIDS Indicator Survey. Ministry of Health Publications, 2011.

[17]. Nelson KE, Williams CM, Graham NM, Balows A. Infectious disease epidemiology theory \& practice.

[18]. Cohn DL, O'Brien RJ, Geiter LJ, Gordin FM, Hershfield E, Horsburgh CR. Targeted tuberculin testing and treatment of latent tuberculosis infection. MMWR Morbidity and Mortality Weekly Report. 2000;49(6):1-54.

[19]. Krleža-Jerić K, Lemmens T. 7th Revision of the Declaration of Helsinki: Good News for the Transparency of Clinical Trials. 2009; Accessed on 23.04.2017 from http://wwwncbinlmnihgov/pmc/articles/PMC26 81053/.

[20]. Cohn DL. Treatment of latent tuberculosis infection: renewed opportunity for tuberculosis control. Clinical Infectious Diseases. 2000 Jul 1;31(1):120-12.

Citation: Isaac O, Felix K, Achilles K, Louis M, Moses N, Annet K, Charles MR Prevalence of Latent Tuberculosis Infection among Paramedical Students in Two Hospitals in Uganda. International Journal of Research Studies in Medical and Health Sciences. 2017;2(4):5-10.

Copyright: (C) 2017 Louis M, et al. This is an open-access article distributed under the terms of the Creative Commons Attribution License, which permits unrestricted use, distribution, and reproduction in any medium, provided the original author and source are credited. 